\title{
Factors influencing anthropogenic carbon dioxide uptake in the North Atlantic in models of the ocean carbon cycle
}

\author{
Robin S. Smith · Jochem Marotzke
}

Received: 2 June 2006/Accepted: 21 December 2007/Published online: 19 January 2008

(C) Springer-Verlag 2008

\begin{abstract}
The uptake and storage of anthropogenic carbon in the North Atlantic is investigated using different configurations of ocean general circulation/carbon cycle models. We investigate how different representations of the ocean physics in the models, which represent the range of models currently in use, affect the evolution of $\mathrm{CO}_{2}$ uptake in the North Atlantic. The buffer effect of the ocean carbon system would be expected to reduce ocean $\mathrm{CO}_{2}$ uptake as the ocean absorbs increasing amounts of $\mathrm{CO}_{2}$. We find that the strength of the buffer effect is very dependent on the model ocean state, as it affects both the magnitude and timing of the changes in uptake. The timescale over which uptake of $\mathrm{CO}_{2}$ in the North Atlantic drops to below preindustrial levels is particularly sensitive to the ocean state which sets the degree of buffering; it is less sensitive to the choice of atmospheric $\mathrm{CO}_{2}$ forcing scenario. Neglecting physical climate change effects, North Atlantic $\mathrm{CO}_{2}$ uptake drops below preindustrial levels between 50 and 300 years after stabilisation of atmospheric $\mathrm{CO}_{2}$ in different model configurations. Storage of anthropogenic carbon in the North Atlantic varies much less among the different model configurations, as differences in ocean transport of dissolved inorganic carbon and uptake of $\mathrm{CO}_{2}$ compensate each other. This supports the idea that measured inventories of anthropogenic carbon in the real ocean cannot be used to constrain the surface uptake. Including physical climate change effects reduces anthropogenic $\mathrm{CO}_{2}$ uptake
\end{abstract}

R. S. Smith · J. Marotzke

Max-Planck Institute for Meteorology, Bundesstrasse 53,

20146 Hamburg, Germany

R. S. Smith $(\square)$

Walker Institute, University of Reading, Reading RG6 6BB, UK

e-mail: r.s.smith@ reading.ac.uk and storage in the North Atlantic further, due to the combined effects of surface warming, increased freshwater input, and a slowdown of the meridional overturning circulation. The timescale over which North Atlantic $\mathrm{CO}_{2}$ uptake drops to below preindustrial levels is reduced by about one-third, leading to an estimate of this timescale for the real world of about 50 years after the stabilisation of atmospheric $\mathrm{CO}_{2}$. In the climate change experiment, a shallowing of the mixed layer depths in the North Atlantic results in a significant reduction in primary production, reducing the potential role for biology in drawing down anthropogenic $\mathrm{CO}_{2}$.

\section{Introduction}

The relatively large carbon inventory of the world ocean, coupled with processes that allow the turnover of this inventory on centennial timescales, mean that knowledge of the processes that regulate the oceanic uptake of carbon dioxide $\left(\mathrm{CO}_{2}\right)$ is a key factor in understanding past and future climate changes (Broecker 1982; Friedlingstein et al. 2005). Since preindustrial times, ocean uptake of $\mathrm{CO}_{2}$ has increased due to increasing quantities of anthropogenic $\mathrm{CO}_{2}$ emitted into the atmosphere (Sabine et al. 2004). The anthropogenic perturbation is difficult to distinguish from the natural carbon in measurements (e.g. Gruber et al. 1996), and uncertainties in both data coverage and the interpretation of that data mean that models of the ocean carbon cycle are an essential tool in ascertaining how anthropogenic $\mathrm{CO}_{2}$ is being taken up by the ocean. The complexity of the marine biogeochemical system, coupled with the wide range of time and space scales on which climate must be studied, has led to the use of a range of 
models of differing sophistication (Lenton et al. 2006; Friedlingstein et al. 2005). Whilst recent model intercomparison projects have shown reasonable agreement among ocean biogeochemical models as regards the global properties of ocean $\mathrm{CO}_{2}$ uptake, considerable differences remain at the regional level (Orr et al. 2001).

Chemically, the distinction between anthropogenic and natural carbon is purely conceptual, but in models it can be precisely diagnosed: either as the difference in carbon fluxes and inventories between modern and preindustrial simulations, or by the use of an artificial tracer. Large intermodel differences in the uptake of anthropogenic $\mathrm{CO}_{2}$ have been found in the North Atlantic, where some of the most intense $\mathrm{CO}_{2}$ uptake is thought to occur (Orr et al. 2001). This enhanced uptake is largely due to the exchange and mixing of surface water with old, relatively carbon poor bottom waters that occurs during the formation of North Atlantic deepwater. Doney et al. (2004) found that much of the difference between the various ocean biogeochemical models could be traced to the background physical state of the models. Models differ significantly in their representation of the ocean in the North Atlantic, due to differences in, for example, convection, the structure of the Atlantic meridional overturning circulation (MOC), and the overflows that link the Atlantic to the Arctic. The modeldependence of these processes also leads to a wide range of model predictions for how the ocean state in the North Atlantic is likely to change in the future (e.g. Gregory et al. 2005). Current and future levels of anthropogenic $\mathrm{CO}_{2}$ uptake in the North Atlantic are thus very uncertain. Although the net $\mathrm{CO}_{2}$ uptake in the North Atlantic is small due to its limited area, uptake in this region represents a disproportionate amount of the inter-model disagreement.

There is also significant disagreement between models and observations of the uptake of anthropogenic $\mathrm{CO}_{2}$ in the North Atlantic. All the models show the North Atlantic as a region of intense uptake of anthropogenic $\mathrm{CO}_{2}$ (Orr et al. 2001), whilst studies based on measurements of carbon in the water calculate that the inventory of anthropogenic carbon in the North Atlantic is almost wholly supplied through transport within the ocean (Roson et al. 2003; Macdonald et al. 2003). However, both the transport-based estimates and the model estimates, as seen above, are subject to significant sources of error. Völker et al. (2002) attempted to constrain the surface $\mathrm{CO}_{2}$ fluxes using a box model and the estimates of anthropogenic carbon in the Atlantic. They found the surface fluxes were not well constrained within their system but that the increasing influence of the buffer effect of ocean dissolved inorganic carbon (DIC) led to a significant reduction of the $\mathrm{CO}_{2}$ uptake in the North Atlantic: uptake dropped below preindustrial levels by the year 2100, despite increasing levels of atmospheric $\mathrm{CO}_{2}$. Uptake below preindustrial levels can be seen as an "outgassing" of the anthropogenic component of the $\mathrm{CO}_{2}$ flux. Although tentative, there is some observational evidence that $\mathrm{CO}_{2}$ uptake in the North Atlantic is currently decreasing (Lefevre and Watson 2004; Omar and Olsen 2006).

In this study, we aim to investigate the factors that influence the uptake and storage of anthropogenic carbon in different ocean general circulation/carbon cycle models, with particular focus on the influence of the ocean physics in the North Atlantic region. Using a variety of configurations to represent the range of models currently in use, we attempt to separate the influences of model resolution and boundary conditions, and to investigate how the modelled evolution of $\mathrm{CO}_{2}$ uptake depends on the build-up of DIC in the North Atlantic, changes in surface state and changes in ocean circulation. We also investigate whether the outgassing of anthropogenic $\mathrm{CO}_{2}$ found by Völker et al. (2002) can be reproduced in a more sophisticated ocean model, and on what timescale it might be expected to occur in reality.

The paper is arranged as follows. In Sect. 2 we describe the models and their background states. In Sect. 5 we investigate the effects of increasing atmospheric $\mathrm{CO}_{2}$ whilst keeping the physical ocean state constant. In Sect. 8 the physical ocean state is also allowed to change in response to the increased $\mathrm{CO}_{2}$ forcing. A discussion and conclusions follow in Sects. 9 and 10.

\section{Models and experiment description}

\subsection{Models}

To cover the range of ocean carbon cycle models currently in use in Earth System Models (ESMs), we use two different versions of the Hamburg Ocean Carbon Cycle (HAMOCC) biogeochemical model, coupled offline to two different ocean circulation models. Offline coupling means that the biogeochemistry model is run using the archived results of a previous ocean circulation model run; the biogeochemistry is thus unable to feed back onto the ocean dynamics. HAMOCC is an NPZD (nutrient, phytoplankton, zooplankton, and detritus) model with a simplified representation of plankton productivity which assumes perfect stoichiometric relationships.

To represent the lower resolution end of ESMs, we use version 3 of HAMOCC (Maier-Reimer 1993), forced offline with temperature, salinity, velocity, and convective adjustment fields generated by the Large-Scale Geostrophic (LSG) ocean model. LSG is an E-grid, z-level, large-scale geostrophic ocean model with 15 vertical layers and a simple sea-ice parameterisation. It uses an upwind advective scheme, and simple vertical/horizontal tracer 
diffusion. LSG runs with a 1 month timestep, at approximately $4^{\circ}$ horizontal resolution. Surface fluxes of $\mathrm{CO}_{2}$ in HAMOCC 3 are calculated via a simple piston velocity approach using constant values for the exchange rate.

To represent the higher resolution components used by some ESMs, we use version 5 of HAMOCC (Maier-Reimer et al. 2005), forced offline by the Max Planck Institute Ocean Model (MPI-OM) (Marsland et al. 2003). HAMOCC5 uses the same carbon chemistry as HAMOCC3, but nitrogen, opal, calcium carbonate, dissolved iron, and dust are also accounted for; production can therefore become iron limited in certain regions. Surface fluxes of $\mathrm{CO}_{2}$ in HAMMOC5 are dependent on the local wind speed, with the Schmidt number and piston velocity calculated according to Wanninkhof (1992). MPI-OM is a primitive equation, z-level model. It runs on an orthogonal, curvilinear C-grid. The model has a nominal $3^{\circ}$ horizontal resolution, but the use of a curvilinear grid results in an approximately $1^{\circ}$ resolution in the North Atlantic, increasing to $\sim 0.5^{\circ}$ in some of the convection regions around Greenland. It has 40 vertical levels. The model uses a total variation diminishing (TVD) advection scheme and GentMcWilliams isopycnal tracer diffusion and eddy parameterisation, with diapycnal mixing based on the scheme of Pacanowski and Philander (1981). To save computational time, the offline biogeochemical tracers are advected along vertical/horizontal gridbox lines, not in isopycnal coordinates: whilst the advection of temperature and salinity along isopycnals is important for the accurate representation of the flow and tracer distribution, the choice of vertical or diapycnal mixing for the biogeochemical tracers in MPIOM/HAMOCC5 makes little difference to the resulting tracer distribution (P. Wetzel, personal communication).

The offline version of HAMOCC5 is driven by monthly averaged data of solar radiation, surface winds, sea surface height, temperature, salinity, velocity, vertical diffusivity, and ice coverage. These data are linearly interpolated in time (using the method of Killworth 1996 to retain the same mean statistics as the monthly fields) to provide daily forcing fields. The use of monthly averaged data reduces the level of variability that the offline version of HAMOCC5 is capable of representing; we aim however to look at general, long-term trends in the model, for which a monthly forcing frequency is suitable. However, the long-term mean may also be affected by the monthly averaging, most likely through the averaging of diapycnal mixing, as the timescales on which convective processes occur are of the order of days within the original model runs. Convective effects are parameterised in MPI-OM through large increases in vertical diffusivity, which are then seen by the offline HAMOCC5 through the monthly averaged vertical diffusivity forcing. The averaging, however, changes the character of the convective mixing from a fast, strong event to a slower, weaker one. Comparisons of online and offline versions of MPI-OM/ HAMOCC5 (the online model has coupling between the dynamics and the biogeochemistry every timestep as the dynamical model is run) forced by the Ocean Model Intercomparison Project (OMIP) surface climatology (Röske 2005) show that the monthly averaging of the diapycnal mixing does not have a major effect on the surface $\mathrm{CO}_{2}$ fluxes simulated over most of the global ocean. The main differences are in the North Atlantic, where the monthly averaging of diapycnal mixing results in slightly too much $\mathrm{CO}_{2}$ uptake (Fig. 1).

\subsection{Experiment description}

In all but one of the following experiments an idealised $\mathrm{CO}_{2}$ forcing is used, where a spatially constant atmospheric $p \mathrm{CO}_{2}$ increases from $278 \mu \mathrm{atm}$. at the rate of $1 \%$ year $^{-1}$ from model year 150 onwards. Past year 289 it is stabilised at four times its initial value $(1,112 \mu \mathrm{atm}$.). This forcing scenario is referred to as $4 \mathrm{xCO} 2$. This idealised $\mathrm{CO}_{2}$ forcing is a standard scenario used in the Coupled Model Intercomparison Project (http://www-pcmdi.llnl.gov/ projects/cmip). For the experiments in Sect. 5, the $\mathrm{CO}_{2}$ forcing in the atmosphere only affects the biogeochemistry, not the physical ocean state. The biogeochemical effects of the increase can thus be separated from those of a changing ocean state, which will also affect $\mathrm{CO}_{2}$ uptake.

We consider two principal experiments with the LSG/ HAMOCC3 model: a control run with fixed preindustrial atmospheric $\mathrm{CO}_{2}$ (L-CTRL) and a run with the $4 \times \mathrm{xCO} 2$ forcing (L-4xCO2). The ocean state used with the offline biogeochemistry in both cases has been forced by restoring to boundary conditions representing a fixed preindustrial climate (Maier-Reimer et al. 1993). An additional experiment is conducted with the LSG/HAMOCC3 model where atmospheric $p \mathrm{CO}_{2}$ follows historical concentrations from 1860 to the year 1990 , and then increases at $1 \%$ year $^{-1}$ until it reaches 650 atm., where it is held steady. This forcing scenario is referred to as L-650. This experiment allows the influence of the choice of forcing scenario to be assessed for the LSG/HAMOCC3.

Two configurations of the MPI-OM/HAMOCC5 are used with the $4 \mathrm{xCO} 2$ forcing. In one, the ocean has been forced by surface boundary fluxes from the OMIP climatology (Röske 2005). The other uses ocean states taken from runs where the MPI-OM been coupled to the ECHAM5 atmosphere model (Jungclaus et al. 2005). ECHAM5 (Roeckner et al. 2003) is a primitive equation atmospheric general circulation model (GCM), run here at a T31 spectral resolution (approximately $3.75^{\circ}$ ) with 19 vertical layers. Dust is provided by a fixed climatology 

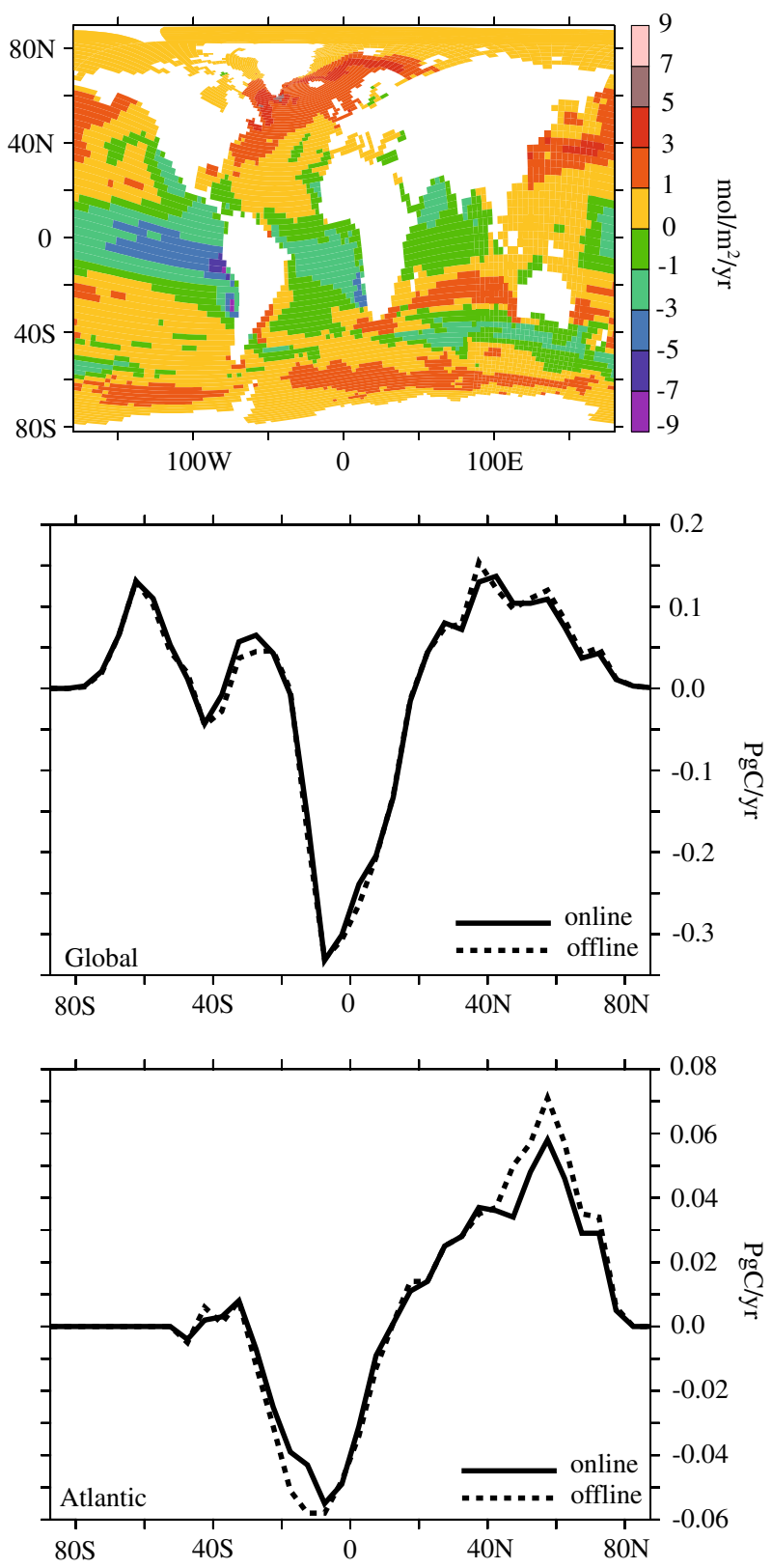

Fig. 1 Ocean $\mathrm{CO}_{2}$ uptake (positive for a net flux from the atmosphere to the ocean) in the MPI-OM/HAMOCC5 model for an uncoupled ocean run forced by OMIP surface forcing. Top annual average uptake from the offline model. Middle total zonal uptake for the global ocean for online (solid) and offline (dashed) versions of the model. Bottom total zonal uptake for the Atlantic basin for online (solid) and offline (dashed) versions of the model

(Timmreck and Schulz 2004). As with the other experiments in this study, atmospheric $p \mathrm{CO}_{2}$ is spatially constant. Using the OMIP-forced MPI-OM/HAMOCC5, we produce a control run with no $\mathrm{CO}_{2}$ forcing (MO-CTRL) and a run with the $4 \mathrm{xCO} 2$ forcing scenario (MO-4xCO2). We also run the MPI-OM/HAMOCC5 model with ocean fields from the coupled ECHAM5/MPI-OM with the same forcings (MC-CTRL and MC-4xCO2).
In Sect. 8, we conduct an additional experiment where the atmospheric $p \mathrm{CO}_{2}$ changes are allowed to affect the physical ocean state as well as the biogeochemistry. Because of the need for an estimate of climate change for this experiment, we only use fields from the coupled ECHAM5/MPI-OM model. This experiment is denoted MC-CLIM. Table 1 summarises the key features of each experiment analysed in this study.

\section{Fixed ocean background states}

\subsection{Control runs}

The flux of $\mathrm{CO}_{2}$ at the ocean surface is set by the difference between atmospheric and ocean $p \mathrm{CO}_{2}$, and the piston velocity. Since atmospheric $p \mathrm{CO}_{2}$ is prescribed, the fluxes depend simply on the modelled ocean $p \mathrm{CO}_{2}$ (assuming constant piston velocity). Ocean $p \mathrm{CO}_{2}$ is set by the surface values of temperature (SST), salinity (SSS), dissolved inorganic carbon (DIC) and alkalinity (Alk). As a result of different boundary conditions and model processes, the different control experiments have different surface distributions of these four tracers, and thus different $\mathrm{CO}_{2}$ fluxes. The surface conditions affect not only the $\mathrm{CO}_{2}$ fluxes in the control experiments, but also the sensitivity of the model to atmospheric $\mathrm{CO}_{2}$ forcing. We thus start by assessing the control runs, with special emphasis on the North Atlantic region.

There are three different control runs in this study. The L-CTRL run is started from the equilibrium preindustrial state of Maier-Reimer et al. (1993). The MO-CTRL run is started from a spun-up state of the online MPI-OM/HAMOCC5 model forced with the OMIP boundary conditions, and then run on for 1,000 years with the offline version of the model. The MC-CTRL run is started from the same spun-up online model state as MO-CTRL, and the offline model is then run for about 1,000 years using ocean fields derived from a preindustrial run of the coupled ECHAM5/MPI-OM model. The North Atlantic region is defined so that the surface area is the same for the LSG/HAMOCC3 runs as for the MPI-OM/HAMOCC5 ones, as far as the grids allow. Surface integral values can thus be compared.

All of the models have a reasonable surface temperature distribution in the North Atlantic (Fig. 2). Average values for the North Atlantic surface conditions are given in Table 2. The lower vertical resolution and higher diapycnal mixing of the LSG model (it has a $50 \mathrm{~m}$ surface layer, the MPI-OM surface layer is $12 \mathrm{~m}$ ) gives it a cooler surface. A cooler surface implies a higher surface DIC content, as $\mathrm{CO}_{2}$ is more soluble in cold water. The MC-CTRL run is also rather cold at the surface, probably a result of a weak 
Table 1 Table of experiments analysed

\begin{tabular}{lllll}
\hline Experiment & Ocean model & Atmosphere model & Climate change & $\mathrm{CO}_{2}$ forcing \\
\hline L-CTRL & LSG/HAMOCC3 & None & No & Static \\
L-4xCO2 & LSG/HAMOCC3 & None & No & No \\
L-650 & LSG/HAMOCC3 & None & No & Static \\
MO-CTRL & MPI-OM/HAMOCC5 & None & No & $4 \times C O 2$ \\
MO-4xCO2 & MPI-OM/HAMOCC5 & None & No & Static \\
MC-CTRL & MPI-OM/HAMOCC5 & ECHAM5 & No & $4 \times C O 2$ \\
MC-4xCO2 & MPI-OM/HAMOCC5 & ECHAM5 & Yes & $4 \times C O 2$ \\
MC-CLIM & MPI-OM/HAMOCC5 & ECHAM5 & \\
\hline
\end{tabular}

In the $4 \mathrm{xCO} 2$ forcing scenario atmospheric $\mathrm{pCO}_{2}$ is increased from $278 \mu \mathrm{atm}$. by $1 \%$ year ${ }^{-1}$ until it reaches $1,112 \mu$ atm., where it is held constant. In the $\mathrm{S} 650 \mathrm{CO}_{2}$ forcing scenario, atmospheric $p \mathrm{CO}_{2}$ follows historical values, from 1860 until 1990, when it then increases at 1\% year $^{-1}$ until it reaches $650 \mu \mathrm{atm}$. and is then held constant

Atlantic MOC failing to transport enough heat to the North Atlantic.

The MC-CTRL state is also not saline enough, which will tend to decrease ocean surface $p \mathrm{CO}_{2}$ slightly. Salinity has a direct effect on the chemical equilibrium of carbon species in the water, but lower salinity also implies a more dilute solution and thus lower levels of DIC and Alk as well. Excess precipitation in MC-CTRL results in a too fresh Atlantic and consequently rather low SSS, DIC and Alk. The effects of dilution can be seen explicitly in the plots of surface Alk and DIC (Fig. 2). Although the climatological data coverage is limited, it can be seen that the over-dilute MC-CTRL has too low levels of DIC and Alk.
The MO-CTRL run has the most realistic SST pattern and a slight overestimate of SSS, resulting in an overestimate surface Alk but a fairly good representation of DIC. Despite only a small overestimate of SSS, L-CTRL overestimates surface DIC and Alk, implying that simple dilution from the surface freshwater balance is not the cause for the overestimates. Overall, the MO-CTRL run has the most realistic surface distributions of SST, SSS, DIC and Alk of the three control runs.

The degree of diapycnal mixing is important for setting the biogeochemical properties of surface water. Remineralisation of organic matter at depth results in a general increase of DIC and Alk with depth, so strong diapycnal
Fig. 2 Surface conditions for the control experiments. The first column shows climatological conditions (SST, SSS from Levitus et al. 1998, Alk and DIC from Key et al. 2004), the second column shows L-CTRL, the third MO-CTRL, and the fourth MC-CTRL. The first row shows SST, the second SSS, the third surface alkalinity, and the fourth surface DIC. Area average values of these fields are given in Table 2. The area defined as the "North Atlantic" is outlined in black
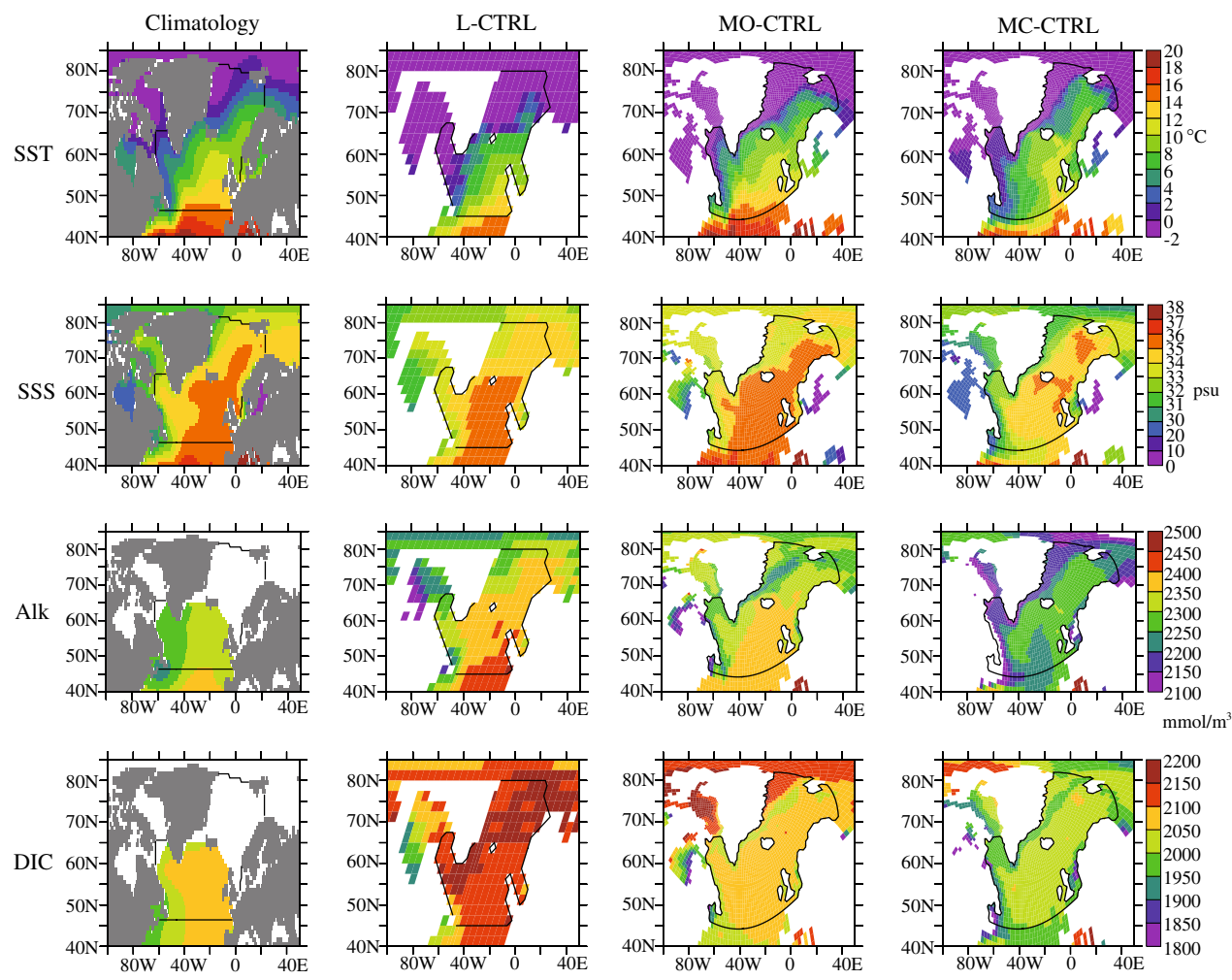
Table 2 Average values of surface conditions in the North Atlantic for the control experiments (see Fig. 2)

\begin{tabular}{lllll}
\hline & Climatology & L-CTRL & MO-CTRL & MC-CTRL \\
\hline SST $\left({ }^{\circ} \mathrm{C}\right)$ & 7.6 & 5.1 & 7.3 & 5.9 \\
SSS $(\mathrm{psu})$ & 34.5 & 34.7 & 34.9 & 33.7 \\
Alk $\left(\mathrm{mmol} / \mathrm{m}^{3}\right)$ & 2,309 & 2,359 & 2,328 & 2,223 \\
DIC $\left(\mathrm{mmol} / \mathrm{m}^{3}\right)$ & 2,059 & 2,137 & 2,067 & 2,006 \\
\hline
\end{tabular}

Climatological data from Levitus et al. (1998) (SST, SSS) and Key et al. (2004) (Alk, DIC)

mixing leads to increased values of DIC, Alk, and nutrients at the surface. Diapycnal mixing is also very important for the response of the ocean to increased atmospheric $\mathrm{CO}_{2}$ forcing, as the rate at which carbon can be mixed down to depth is crucial in setting the rate at which it can be taken up at the surface. Likewise, the strength and nature of the Atlantic MOC are important factors in determining surface $\mathrm{CO}_{2}$ uptake in the North Atlantic. As surface water flows north and cools, its $p \mathrm{CO}_{2}$ drops as it becomes more soluble to $\mathrm{CO}_{2}$. A broader or slower surface flow would have time to come fully into equilibrium with the atmosphere as it flows north, whereas a narrower or faster circulation would not. A stronger MOC also implies an increased rate of diapycnal mixing, often associated with deeper mixed layer depths and convective activity at high latitudes, so MOC strength can be linked to surface concentrations of Alk as well as DIC.

Both the diapycnal mixing and the Atlantic MOC differ among the different experiments. The L-CTRL run has deep mixed layers off the south-eastern tip of Greenland and in the Greenland-Iceland-Norwegian (GIN) seas and a strong, deep MOC with a maximum overturning strength of $24 \mathrm{~Sv}$ at $30^{\circ} \mathrm{N}$ (Fig. 3). MO-CTRL has an equally strong MOC, with the maximum further north a $50^{\circ} \mathrm{N}$, although it is rather shallower. Strong sinking occurs in the Labrador and GIN seas. The MC-CTRL overturning has the same shape as that in MO-CTRL, but is much weaker at $14 \mathrm{~Sv}$. Mixed layer depths are deepest south of Greenland and in the GIN seas, but are about two-thirds of the values of those in the other runs. The low horizontal resolution in the LSG/HAMOCC3 model leads to a northward surface flow from the Equator that is too sluggish and spreads over too wide an area. The cooling flow thus has more time to equilibrate with the atmosphere on its journey northwards, resulting in higher DIC levels in the North Atlantic. The LSG/HAMOCC 3 model also has higher levels of vertical diffusivity, which lead to weaker vertical gradients and higher surface values of Alk and DIC.

\section{2 $\mathrm{CO}_{2}$ forcing experiments}

In the experiments considered in this section, the increased atmospheric $p \mathrm{CO}_{2}$ only affects the biogeochemistry and not the physical ocean state of the models. Thus the temperature, salinity, and alkalinity fields will remain constant (e.g. alkalinity is not affected by $\mathrm{CO}_{2}$ exchange and there is no $\mathrm{CO}_{2}$ fertilisation effect on the biology in the models). Only the surface fluxes of $\mathrm{CO}_{2}$ and the DIC content of the water change during the run.

Ocean $p \mathrm{CO}_{2}$ can be approximately expressed as $p \mathrm{CO}_{2}=$ $\frac{k_{2}}{\left(k_{0} \times k_{1}\right)} \times \frac{(2[\mathrm{DIC}]-[\mathrm{Alk}])^{2}}{([\mathrm{Alk}]-[\mathrm{DIC}])}$, where $k_{0}$ is the constant for $\mathrm{CO}_{2}$ dissolution and $k_{1}$ and $k_{2}$ are the dissociation constants of $\mathrm{CO}_{2}$ in seawater (Sarmiento and Gruber 2006). The $k_{\mathrm{i}}$ are dependent on temperature and salinity, so the fields of SST, SSS, DIC and Alk suffice, under this approximation, to determine the ocean surface $p \mathrm{CO}_{2}$ and thus the flux from the atmosphere in the control runs (this approximation is not used in the models, but it is used here to quickly assess the influences of these four tracer fields). Using this formula with values from Table 2, L-CTRL has the highest
Fig. 3 Top spring mixed layer depths in the North Atlantic for the non-climate change experiments. Mixed layer depth is determined as the depth at which the density difference from the sea surface is 0.125 sigma units. Bottom Atlantic MOC streamfunction (clockwise positive) for the nonclimate change runs. Left $\mathrm{L}$ CTRL, middle MO-CTRL, right MC-CTRL
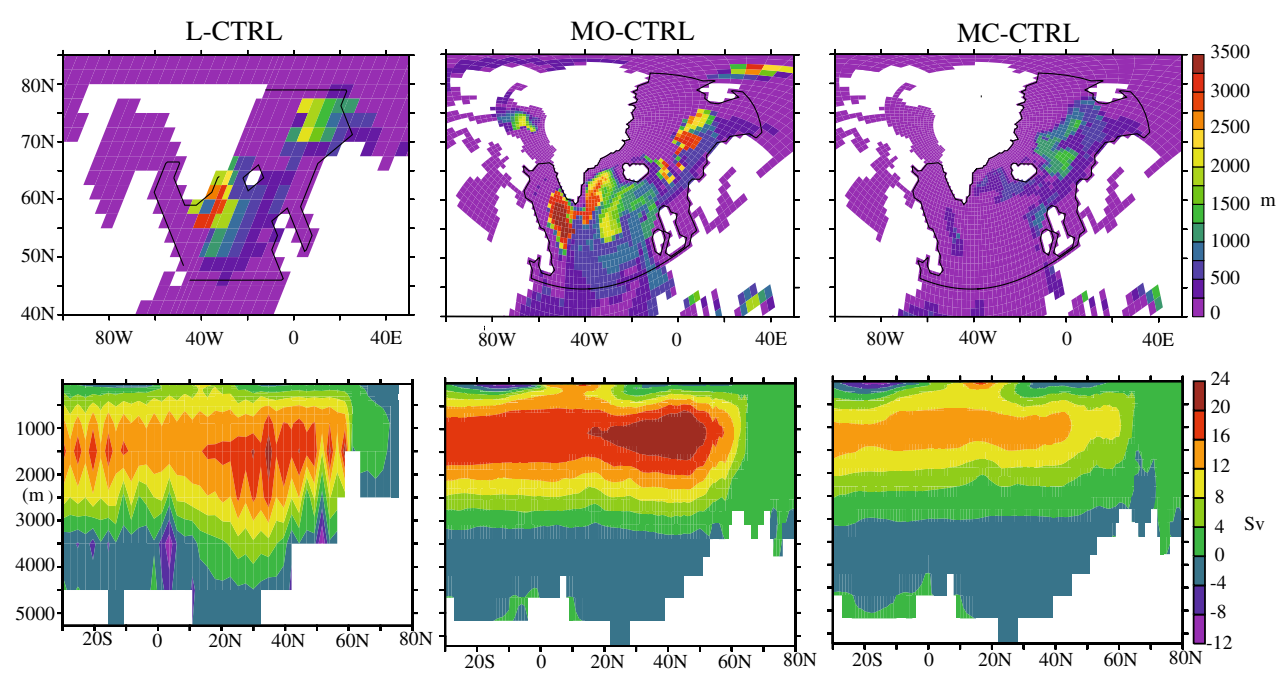
North Atlantic $p \mathrm{CO}_{2}$, followed by MC-CTRL and then MO-CTRL. A higher surface $p \mathrm{CO}_{2}$ implies a lower uptake of $\mathrm{CO}_{2}$ from the atmosphere. This is confirmed by the surface uptake in the three control runs, at $0.21 \mathrm{PgC} /$ year for L-CTRL, 0.28 PgC/year for MC-CTRL and $0.3 \mathrm{PgC} /$ year for MO-CTRL. $\mathrm{CO}_{2}$ uptake in the Atlantic is generally lower in L-CTRL, reflecting the lower resolution, sluggish northward surface flow that has more time to come into equilibrium with the atmosphere.

When $\mathrm{CO}_{2}$ enters the ocean from the atmosphere, much of it reacts with carbonate (the strongest base of the $\mathrm{CO}_{2}$ system) in the water to form bicarbonate ions $\left(\mathrm{CO}_{2(\mathrm{aq})}+\right.$ $\mathrm{CO}_{3}^{2-}+\mathrm{H}_{2} \mathrm{O} \Leftrightarrow 2 \mathrm{HCO}_{3}^{-}$), leaving only a small proportion as dissolved $\mathrm{CO}_{2}$ that contributes to the ocean $\mathrm{pCO}_{2}$. Under current conditions, approximately $95 \%$ of the $\mathrm{CO}_{2}$ entering the ocean from the atmosphere reacts with carbonate in this way. As the reservoir of carbonate ions is reduced by $\mathrm{CO}_{2}$ uptake a greater proportion of the atmospheric $\mathrm{CO}_{2}$ taken up remains in the ocean as dissolved $\mathrm{CO}_{2}$, reducing the seaair $p \mathrm{CO}_{2}$ gradient and hence reducing further $\mathrm{CO}_{2}$ uptake. Over millennial timescales the carbonate reservoir is repopulated by the dissolution of calcium carbonate from sediments, but this recharge is minor on the timescales addressed in this study.

The degree of buffering provided by the carbonate ions against changes in DIC is usually expressed as the Revelle factor, which can be (approximately) calculated as Rev = $\frac{[\mathrm{DIC}]}{p \mathrm{CO}_{2}} \times \frac{d p \mathrm{CO}_{2}}{d[\mathrm{DIC}]}$ (Sarmiento and Gruber 2006). A low Revelle factor indicates that the buffer effect is strong and ocean $p \mathrm{CO}_{2}$ would increase by a small amount as DIC increases, so a given increase in atmospheric $\mathrm{CO}_{2}$ will result in a relatively high ocean uptake before equilibrium between ocean and atmosphere $p \mathrm{CO}_{2}$ is reached.

Conversely, a high Revelle factor implies that ocean $p \mathrm{CO}_{2}$ would increase by a large amount with any increase in atmospheric $p \mathrm{CO}_{2}$, implying a lower uptake of $\mathrm{CO}_{2}$ to reach equilibrium with the atmosphere. Estimating the North Atlantic mean Revelle factor from the surface fields in the control experiments suggests that the L-CTRL $(\operatorname{Rev}=14.0)$ and MC-CTRL $(\operatorname{Rev}=13.9)$ uptake should be about equally sensitive to changes in DIC, whilst the MO-CTRL $(\operatorname{Rev}=12.3)$ runs should be rather less sensitive.

All the model configurations have a similar global mean ocean $\mathrm{CO}_{2}$ uptake in response to the atmospheric $\mathrm{CO}_{2}$ forcing (Fig. 4). As atmospheric $p \mathrm{CO}_{2}$ increases, ocean uptake also increases, up to a peak of about $7 \mathrm{PgC} /$ year for L-CTRL and MC-CTRL, and a slightly higher peak of $7.7 \mathrm{pgC} / \mathrm{year}$ for MO-CTRL. These numbers are in line with those found by previous studies for similar experiments (Sarmiento and Le Quere 1996; Joos et al. 1999).

There is rather more inter-model variation in the $\mathrm{CO}_{2}$ uptake in the North Atlantic (Fig. 4). Uptake in the
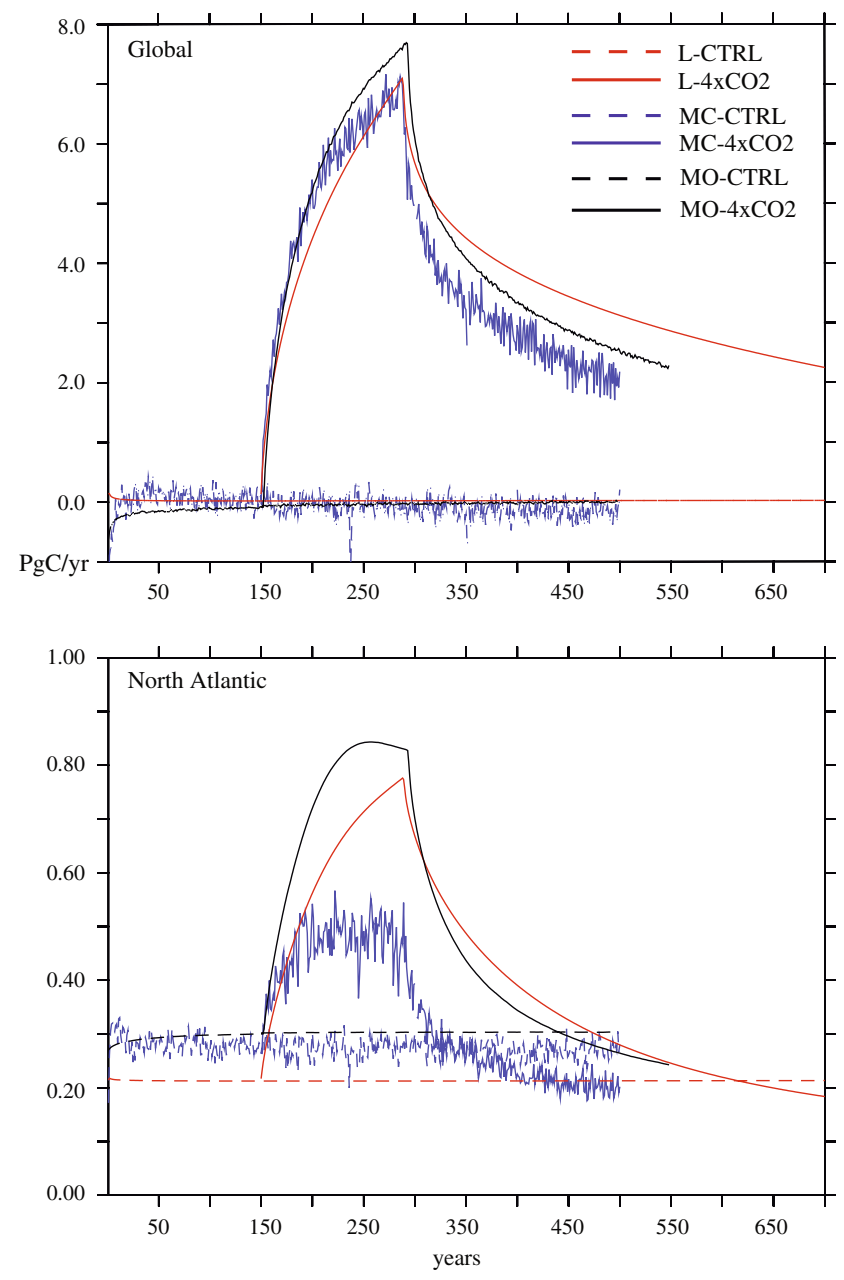

Fig. 4 Ocean uptake of $\mathrm{CO}_{2}$ for the non-climate change experiments. Top global integrated uptake. Bottom North Atlantic uptake. Dashed lines are for the CTRL experiments, solid lines for the $4 \mathrm{xCO} 2$ experiments. Red L-CTRL and L-4xCO2; black MO-CTRL and MO4xCO2; blue MC-CTRL and MC-4xCO2

$\mathrm{L}-4 \mathrm{xCO} 2$ run increases until stabilisation of atmospheric $\mathrm{CO}_{2}$, from $0.21 \mathrm{PgC} /$ year at year 150 to a peak of $0.77 \mathrm{PgC} /$ year at year 290, and then drops back towards equilibrium, reaching its preindustrial value at year 610 (around 320 years after stabilisation of atmospheric $\mathrm{CO}_{2}$ ). After year 610, the reduced carbonate buffer means that $\mathrm{CO}_{2}$ uptake in the North Atlantic is below preindustrial levels, despite the far higher levels of atmospheric $\mathrm{CO}_{2}$. Uptake below preindustrial levels can be seen as "outgassing" of anthropogenic $\mathrm{CO}_{2}$, as suggested by Völker et al. (2002), although here it occurs several centuries after stabilisation of atmospheric $\mathrm{CO}_{2}$, rather than coming 100 years before stabilisation as they found. In the L-650 run with the rather different, weaker $\mathrm{CO}_{2}$ forcing scenario, whilst the maximum $\mathrm{CO}_{2}$ uptake is rather less, the period after which uptake has dropped to below the preindustrial control level is much the same (not shown). 
In the MO-4xCO2 run, North Atlantic $\mathrm{CO}_{2}$ uptake increases more rapidly than in $\mathrm{L}-4 \mathrm{xCO} 2$, from 0.3 to a peak of $0.84 \mathrm{PgC} /$ year. The greater initial uptake is a reflection of the higher carbonate buffer and lower Revelle factor in this run. The rapid increase of DIC causes the Revelle factor to increase noticeably over the duration of the forcing, meaning that the peak ocean uptake occurs before atmospheric $\mathrm{CO}_{2}$ stabilises. The higher Revelle factor then means that ocean $\mathrm{CO}_{2}$ uptake drops more quickly in MO$4 \mathrm{xCO} 2$ than $\mathrm{L}-4 \mathrm{xCO} 2$ once atmospheric $p \mathrm{CO}_{2}$ has stabilised, with uptake dropping below preindustrial levels at year 440 (150 years after stabilisation of atmospheric $\left.p \mathrm{CO}_{2}\right)$. The rate of change of the Revelle factor diagnosed here is also dependent on the rate of mixing of the North Atlantic surface waters. It can still, however, be a useful tool for qualitatively comparing the rate of uptake of $\mathrm{CO}_{2}$ in the different experiments.

North Atlantic $\mathrm{CO}_{2}$ uptake in the MC-4xCO2 run follows a similar general pattern to those in the other runs, although the peak uptake is much less, as is the time required for uptake to drop below preindustrial levels. The maximum uptake in $\mathrm{MC}-4 \mathrm{xCO} 2$ is around $0.5 \mathrm{PgC} /$ year, and, as for MO-4xCO2, it occurs whilst atmospheric $p \mathrm{CO}_{2}$ is still rising. The period over which $\mathrm{CO}_{2}$ uptake is reduced is also less, dropping below preindustrial levels by year 340 (50 years after stabilisation of atmospheric $\mathrm{CO}_{2}$ ). The piston velocity in the MPI-OM/HAMOCC5 model is dependent on the surface winds, but although the North Atlantic wind speeds specified for the MC-CTRL and MC$4 \mathrm{xCO} 2$ runs are about $9 \%$ higher than in the MO-CTRL and $\mathrm{MO}-4 \mathrm{xCO} 2$ runs, North Atlantic $\mathrm{CO}_{2}$ uptake in the $\mathrm{MC}$ experiments is substantially lower than in the MO experiments. The wind-speed effect is clearly outweighed by the other differences between the model states in determining $\mathrm{CO}_{2}$ uptake in the North Atlantic.

Given that the Revelle factor for MC-CTRL is the same as that for the L-CTRL, it is perhaps surprising that their surface flux responses to the $\mathrm{CO}_{2}$ forcing are so different. There are two factors involved here. For one thing, the deeper mixed layers and higher diapycnal mixing in the L-CTRL ocean state mean that excess $\mathrm{CO}_{2}$ is moved from the surface layers to depth in the North Atlantic at a faster rate than in MC-CTRL. The reservoir of water coming into equilibrium with atmospheric $p \mathrm{CO}_{2}$ in $\mathrm{MC}-4 \times \mathrm{xCO} 2$ is thus effectively smaller, and it comes into equilibrium with the atmosphere more quickly. The second factor involves the different equilibrium levels of DIC found in the North Atlantic in the control runs. The Revelle factors of 13.9 and 14.0 calculated for the L-CTRL and MC-CTRL surface oceans respectively, imply that a $1 \%$ change in DIC will lead to a $\sim 14 \%$ change in ocean $p \mathrm{CO}_{2}$. Both $\mathrm{L}-4 \mathrm{xCO} 2$ and $\mathrm{MC}-4 \mathrm{xCO} 2$ accumulate similar amounts of anthropogenic DIC in their surface waters during the period of atmospheric forcing (Fig. 5), but the increases in anthropogenic DIC represent larger percentage DIC changes in $\mathrm{MC}-4 \mathrm{xCO} 2$ than in $\mathrm{L}-4 \mathrm{xCO} 2$, as the MC-CTRL run underestimated surface DIC whilst the L-CTRL overestimated it. The larger percentage DIC changes in MC$4 \times \mathrm{xCO} 2$ also lead to larger absolute changes in $p \mathrm{CO}_{2}$ than in $\mathrm{L}-4 \mathrm{xCO} 2$, as $\mathrm{MC}-4 \mathrm{xCO} 2$ started with higher $p \mathrm{CO}_{2}$ values than $\mathrm{L}-4 \mathrm{xCO} 2$. The larger $p \mathrm{CO}_{2}$ changes in $\mathrm{MC}-4 \mathrm{xCO} 2$ mean that the air-sea gradient of $\mathrm{CO}_{2}$ reduces much more quickly than in $\mathrm{L}-4 \times \mathrm{xO} 2$, leading to the lower overall $\mathrm{CO}_{2}$ uptake in $\mathrm{MC}-4 \mathrm{xCO} 2$.

DIC storage in the Atlantic for the CTRL runs (Fig. 5, left) reflects the influences already discussed for the surface. The L-CTRL run clearly has elevated levels of DIC throughout the water column compared to both MO-CTRL and MC-CTRL, and the higher levels of diapycnal diffusion in the low-resolution model result in a more vertically homogeneous picture. In $\mathrm{MO}-4 \mathrm{xCO} 2$, the vigorous MOC can be seen in the southward reach of the North Atlantic Deep Water. Model differences in the distribution of the additional anthropogenic $\mathrm{CO}_{2}$ in the Atlantic (Fig. 5, middle, right) seem rather smaller. The initially high uptake seen in the MO-4xCO2 run is evident in the DIC inventory at 300 years, but by 500 years the distributions, at least in the North Atlantic, do not look too different. It is notable, however, that the $\mathrm{L}-4 \mathrm{xCO} 2$ run still shows a more vertically homogeneous water column, and the weaker diapycnal mixing in the $\mathrm{MC}-4 \mathrm{xCO} 2$ run can be seen in the deep water north of $70^{\circ} \mathrm{N}$ which sees no anthropogenic $\mathrm{CO}_{2}$. Observation-based assessments of anthropogenic $\mathrm{CO}_{2}$ in the Atlantic (e.g. Sabine et al. 2004) show similar patterns of storage, with high concentrations at the surface and anthropogenic $\mathrm{CO}_{2}$ being found at greater depths at higher latitudes, particularly in the northern hemisphere. The idealised $\mathrm{CO}_{2}$ concentration scenarios used in our runs mean that it is difficult to compare the magnitude of anthropogenic $\mathrm{CO}_{2}$ storage in the experiments with observations, but the patterns of storage can still be examined. Compared to Sabine et al. (2004), anthropogenic $\mathrm{CO}_{2}$ storage in the $\mathrm{L}-4 \mathrm{xCO} 2$ run is too deep and vertically homogeneous, whilst the anthropogenic $\mathrm{CO}_{2}$ found at depth further south in the MO-4xCO2 run, a result of the vigorous $\mathrm{MOC}$, also looks unrealistic. Of the three $4 \mathrm{xCO} 2$ runs, anthropogenic $\mathrm{CO}_{2}$ storage in the $\mathrm{MC}-4 \mathrm{xCO} 2$ run has the most realistic pattern.

The inventory of North Atlantic anthropogenic DIC varies between models much less than the surface uptake of anthropogenic $\mathrm{CO}_{2}$ (Fig. 6, top, middle). Conservation of mass implies that the difference between the DIC inventory change and the input from surface uptake must be provided by transport of DIC in the ocean. Clearly, the ocean DIC transport must be different in the different model configurations. 

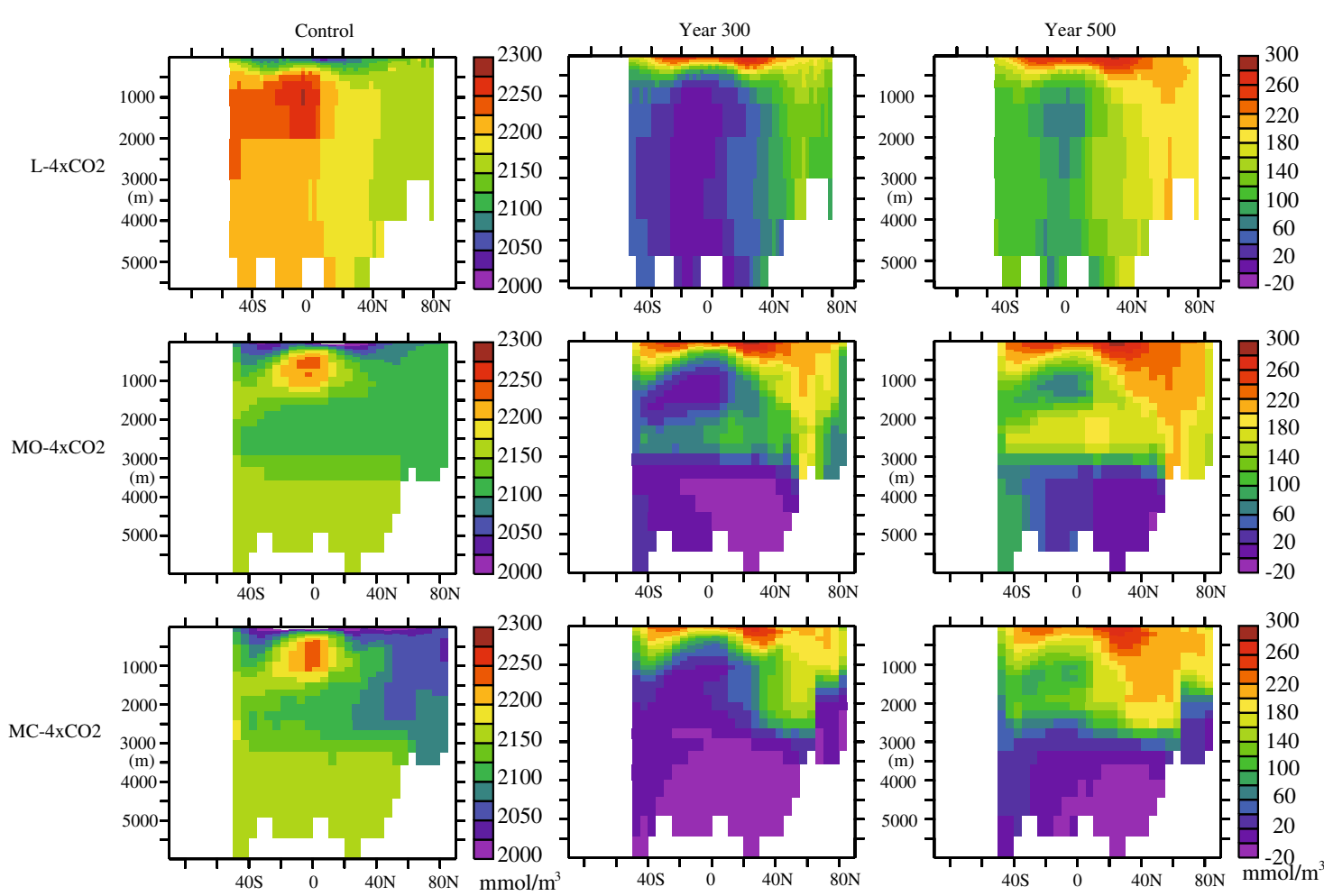

Fig. 5 Zonal average DIC for the Atlantic for the non-climate change experiments. The left-most column shows the control DIC levels at year 150 before the $\mathrm{CO}_{2}$ forcing has started, the middle and right

All the experiments show a net export of DIC from the North Atlantic region throughout the runs (Fig. 6 bottom). For the $\mathrm{L}-4 \mathrm{xCO} 2$ and the $\mathrm{MO}-4 \mathrm{xCO} 2$ experiments, net DIC export increases with the increase in $\mathrm{CO}_{2}$ forcing and uptake at the surface. The $\mathrm{MC}-4 \mathrm{xCO} 2$ run is, however, rather different: net export of DIC from the North Atlantic is reduced as atmospheric forcing increases. A reduction in net export could be due to a decrease in export of DIC at depth (assuming constant import at the surface), or an increase in surface import of DIC (assuming a constant export). As DIC in the North Atlantic has increased, it is unlikely that the change in net export would come from a reduction in DIC export at depth. This implies that there is an increase in the import of anthropogenic DIC to the North Atlantic in the MC-4xCO2 run that is greater than the export at depth. This is supported by the changes further south in the Atlantic. All of the $4 \mathrm{xCO} 2$ experiments have the same uptake of $\mathrm{CO}_{2}$ further south in the Atlantic, and the same import of DIC into the North Atlantic. Given that MC-CTRL has much lower values of DIC in the North Atlantic than the other runs, the imported anthropogenic DIC is relatively more important for the North Atlantic inventory in the MC-4xCO2 run than in the other runs. The higher ocean transport of anthropogenic DIC in the MC$4 \mathrm{xCO} 2$ run explains why the change in the North Atlantic inventory of anthropogenic DIC is the same as for the other columns show the anthropogenic DIC perturbation for years 300 and 500 , respectively. The top row shows $\mathrm{L}-4 \mathrm{xCO} 2$, the middle MO$4 \times \mathrm{CO} 2$, and the bottom $\mathrm{MC}-4 \times \mathrm{CO} 2$

experiments, despite much lower surface uptake of anthropogenic $\mathrm{CO}_{2}$ in $\mathrm{MC}-4 \mathrm{xCO} 2$.

\section{Climate change experiments}

In the previous experiments the $\mathrm{CO}_{2}$ forcing only affected the biogeochemistry and not the underlying ocean state. An increase in atmospheric $\mathrm{CO}_{2}$ would, in reality, cause a physical climate change, with changes in temperature and salinity and knock-on effects on DIC and Alk separate from the purely chemical aspects of the $\mathrm{CO}_{2}$ forcing that were investigated above. Changes in temperature affect the solubility of $\mathrm{CO}_{2}$ in the ocean, and changes in mixed layer depths or the strength of the MOC would be expected to have a significant impact on $\mathrm{CO}_{2}$ uptake in the North Atlantic. In this section, we analyse an experiment (MCCLIM) where the $\mathrm{CO}_{2}$ forcing has been allowed to modify the physical ocean state.

The time-dependent ocean state for MC-CLIM was derived from a run of the ECHAM5/MPI-OM model, started from the MC-CTRL state and forced with the $4 x C O 2$ scenario. By year 500 (350 years after the start of the forcing), the global surface ocean has warmed by $6{ }^{\circ} \mathrm{C}$, and the MOC has reduced by $66 \%$, from 15 to $5 \mathrm{~Sv}$ (Fig. 7). The deepest mixed layer depths are found in much 

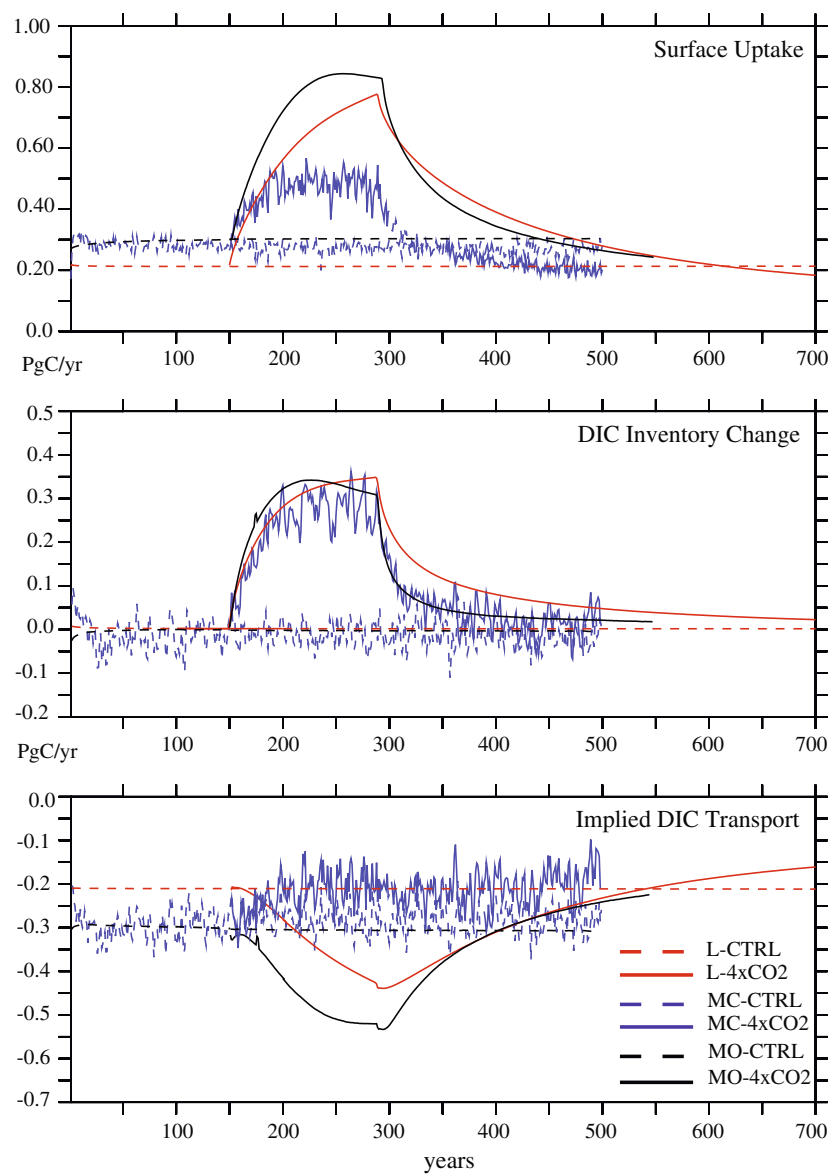

Fig. 6 North Atlantic $\mathrm{CO}_{2}$ budgets for the non-climate change experiments. Top is the surface uptake (as in Fig. 4), middle change in DIC inventory, and bottom ocean transport of DIC implied by the difference of the two panels above. A positive residual indicates transport of DIC into the North Atlantic. Dashed lines are CTRL runs, and solid the $4 \times \mathrm{xCO} 2$ experiments. Red L-CTRL and L-4xCO2; black MO-CTRL and MO-4xCO2; blue MC-CTRL and MC-4xCO2.

the same place as in the MC-CTRL run, but are much reduced, to a maximum of $750 \mathrm{~m}$ in the spring. Wind speeds in the North Atlantic steadily decline by $4 \%$ over the course of the run. The North Atlantic region warms by about $5^{\circ} \mathrm{C}$, and becomes 1.8 psu less saline due to a more active hydrologic cycle. Much of the warming in the North Atlantic is linked to the retreat of sea-ice and the loss of the sea ice albedo effect. The dilution implied by the reduction in salinity also acts to reduce the alkalinity and DIC concentrations further from the rather low levels already seen for the MC-CTRL experiment. There is also a reduction in biological activity, resulting from a reduction in diapycnal mixing which diminishes the supply of nutrients to the surface (Fig. 8), with both phosphate and nitrate significantly reduced.

Globally, the physical ocean state changes here reduce the maximum surface $\mathrm{CO}_{2}$ uptake from $7 \mathrm{PgC}$ /year for $\mathrm{MC}-4 \mathrm{xCO} 2$ to about 5.5 PgC/year. This level of reduction is in line with previous studies, which have found that global $\mathrm{CO}_{2}$ uptake is significantly reduced by climate change, mostly due to the effects of warming and reductions in the MOC and deepwater formation (Sarmiento and Le Quere 1996; Joos et al. 1999).

As the $\mathrm{CO}_{2}$ forcing increases, the surface uptake of $\mathrm{CO}_{2}$ initially increases. However, the peak uptake occurs just before year 200, and then starts to decline again despite a constantly increasing atmospheric forcing (Fig. 9 top). By year 290, when atmospheric $\mathrm{CO}_{2}$ stabilises, $\mathrm{CO}_{2}$ uptake is already reduced back to its preindustrial value, and continues to drop further. The rather rapid reduction of the $\mathrm{CO}_{2}$ uptake seen for the MC-4xCO2 run is clearly exacerbated by the changes in physical ocean state that occur here. The increase in SST acts to increase ocean $p \mathrm{CO}_{2}$, and whilst the reduction in SSS acts to decrease $p \mathrm{CO}_{2}$, the sensitivity of $p \mathrm{CO}_{2}$ to this salinity change is smaller than to the temperature change. The slight drop in wind speeds during the run also acts to inhibit $\mathrm{CO}_{2}$ uptake. Surface Alk in the North Atlantic decreases, a combination of the dilution implied by the drop in salinity and the reduction in diapycnal mixing associated with reduced deepwater formation. Despite these factors, surface DIC still increases due to the atmospheric $p \mathrm{CO}_{2}$ forcing. Ocean $p \mathrm{CO}_{2}$ tends to increase as Alk decreases, so the trends in Alk and DIC imply a rapid erosion of the uptake capacity in MC-CLIM. The steady change in surface temperature and alkalinity, combined with the reduction in diapycnal mixing that is associated with the reduction in deepwater formation, explains why the shape of the uptake curve is different in MC-CLIM.

Changes in DIC levels integrated over the whole depth of the North Atlantic show a timing similar to that of the surface uptake (Fig. 9 middle), and the change in column DIC peaks at the same time as the surface uptake does. North Atlantic DIC inventory values do now change significantly along with the different surface uptake, in contrast to the behaviour noted in the previous section. Surface DIC values are considerably lower than in the MC$4 \mathrm{xCO} 2$ run, showing that the changes in the physical ocean state increase the Revelle factor so much that even small increases in DIC serve to equilibrate ocean $p \mathrm{CO}_{2}$ to the atmospheric forcing.

The ocean transport of anthropogenic DIC implied by the difference of the surface uptake and the inventory change follows a similar pattern to that seen for the MC$4 \mathrm{xCO} 2$ run. There is an immediate reduction in the export of DIC from the North Atlantic: export drops until atmospheric $\mathrm{CO}_{2}$ stabilises in year 290 when equilibrium between surface uptake and regional export is reestablished. As with the $\mathrm{MC}-4 \mathrm{xCO} 2$ run, the reduction in DIC export can be seen as a net import and storage of anthropogenic DIC in the North Atlantic throughout the 
Fig. 7 North Atlantic ocean state changes in the MC-CLIM experiment. Top left $\mathrm{MOC}$ strength at $30^{\circ} \mathrm{N}$. Bottom left North Atlantic average SST. Top right North Atlantic average SSS. Bottom right North Atlantic average alkalinity
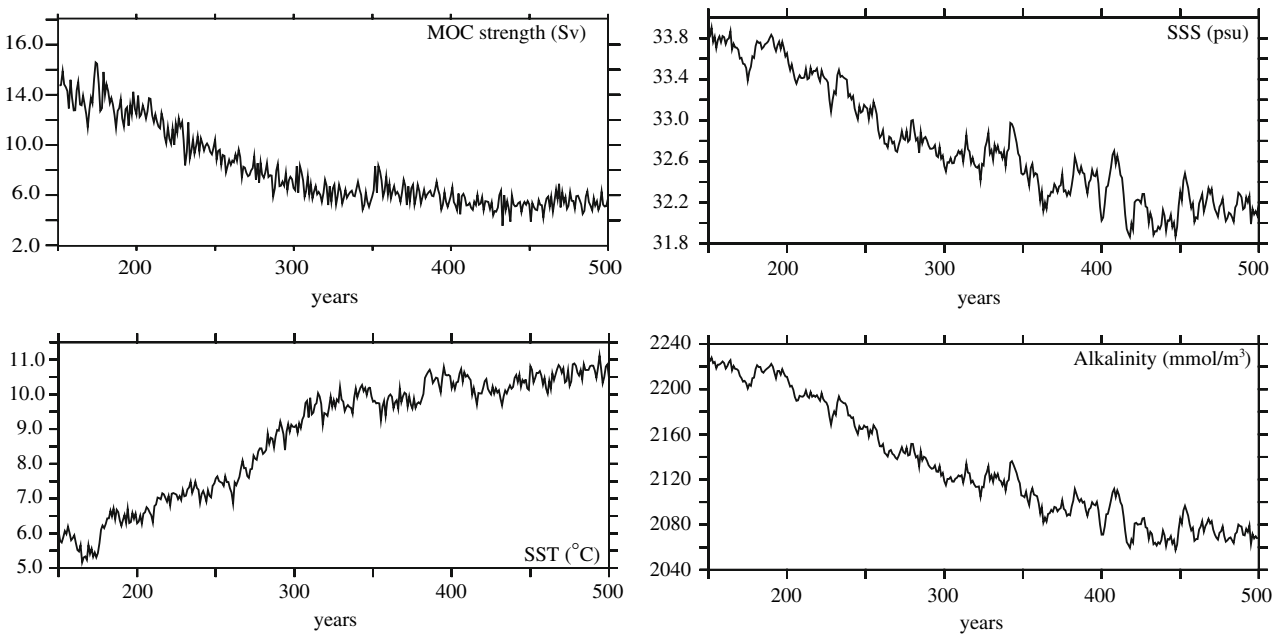

Fig. 8 Annual mean column integrated phytoplankton concentration in the North Atlantic. Left MC-CTRL. Right MC-CLIM at 500 years. The area defined as the "North Atlantic" is outlined in black
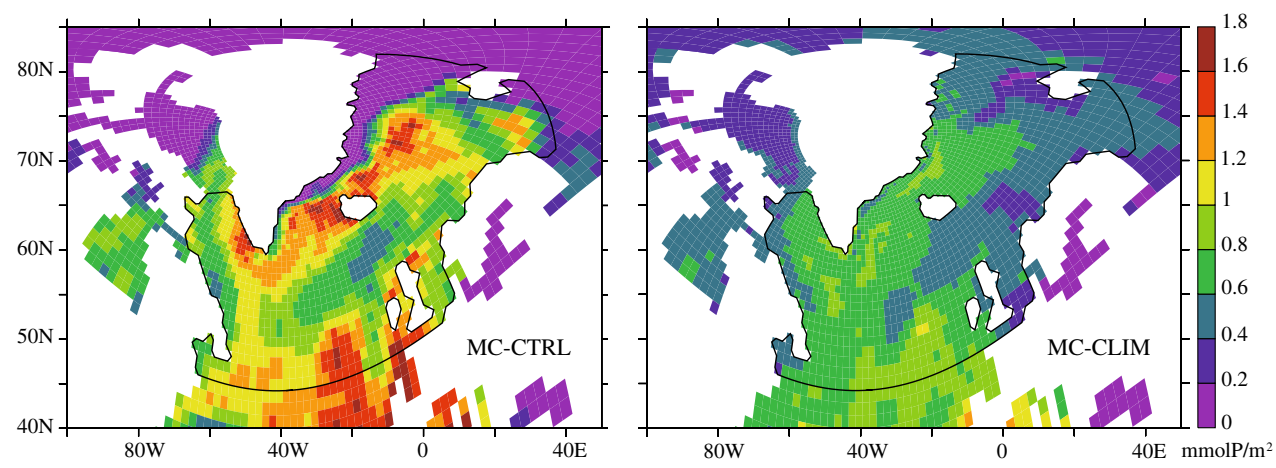

experiment. The reduction in the MOC seen in the MCCLIM experiment clearly plays a role in the further reduction in net export of anthropogenic DIC from the North Atlantic.

Climate change induced by anthropogenic $\mathrm{CO}_{2}$ is expected to have some impact on marine biology, which would be expected to affect ocean $\mathrm{CO}_{2}$ chemistry. There is, however, great uncertainty in how to model biology under different climate conditions. Whilst increased $\mathrm{CO}_{2}$ fertilisation is not expected to have a significant direct impact on biology, changes in temperature, acidification, and nutrient availability are likely to be important. Very little is known about how the population dynamics of marine ecosystems may change in the future. Previous studies (e.g. Sarmiento and Le Quere 1996; Joos et al. 1999; MaierReimer et al. 1996) have chosen either to exclude biology, or to use schemes where biological carbon fluxes are either kept constant, reduced to zero or increased to a theoretical maximum in order to cover a range of possibilities. These studies have found that biological effects have the potential to reduce the impact of climate change on ocean $\mathrm{CO}_{2}$ uptake: for instance, Sarmiento and Le Quere (1996) found that reductions in diapycnal mixing associated with shutdown of the MOC led to a net increase in downward carbon fluxes associated with biological activity, reducing surface $p \mathrm{CO}_{2}$ and mitigating the reduction in $\mathrm{CO}_{2}$ uptake. Whilst the simple NPZD biology used here cannot model significant changes in ecosystem dynamics, we find that increased stratification associated with the reduction in deepwater formation leads to a significant reduction in the phytoplankton concentration due to the reduction in upwelled nutrients (Fig. 8). Under these circumstances it seems unlikely that biology could significantly compensate for any of the other physical effects seen to reduce $\mathrm{CO}_{2}$ uptake in the North Atlantic under climate change.

\section{Discussion}

We have shown that there is a significant degree of model dependency in the sensitivity of North Atlantic $\mathrm{CO}_{2}$ uptake to increased atmospheric $\mathrm{CO}_{2}$. This sensitivity affects both the magnitude of the uptake, and the timescales on which it returns to preindustrial levels. Excluding climate change effects, the experiments here show peak uptakes of between 0.55 and $0.25 \mathrm{PgC} /$ year of anthropogenic $\mathrm{CO}_{2}$, with periods of between 300 and 50 years after stabilisation of atmospheric $\mathrm{CO}_{2}$ for the uptake to drop below its preindustrial value. Including climate change effects, which would also be seen in reality, reduces the total 

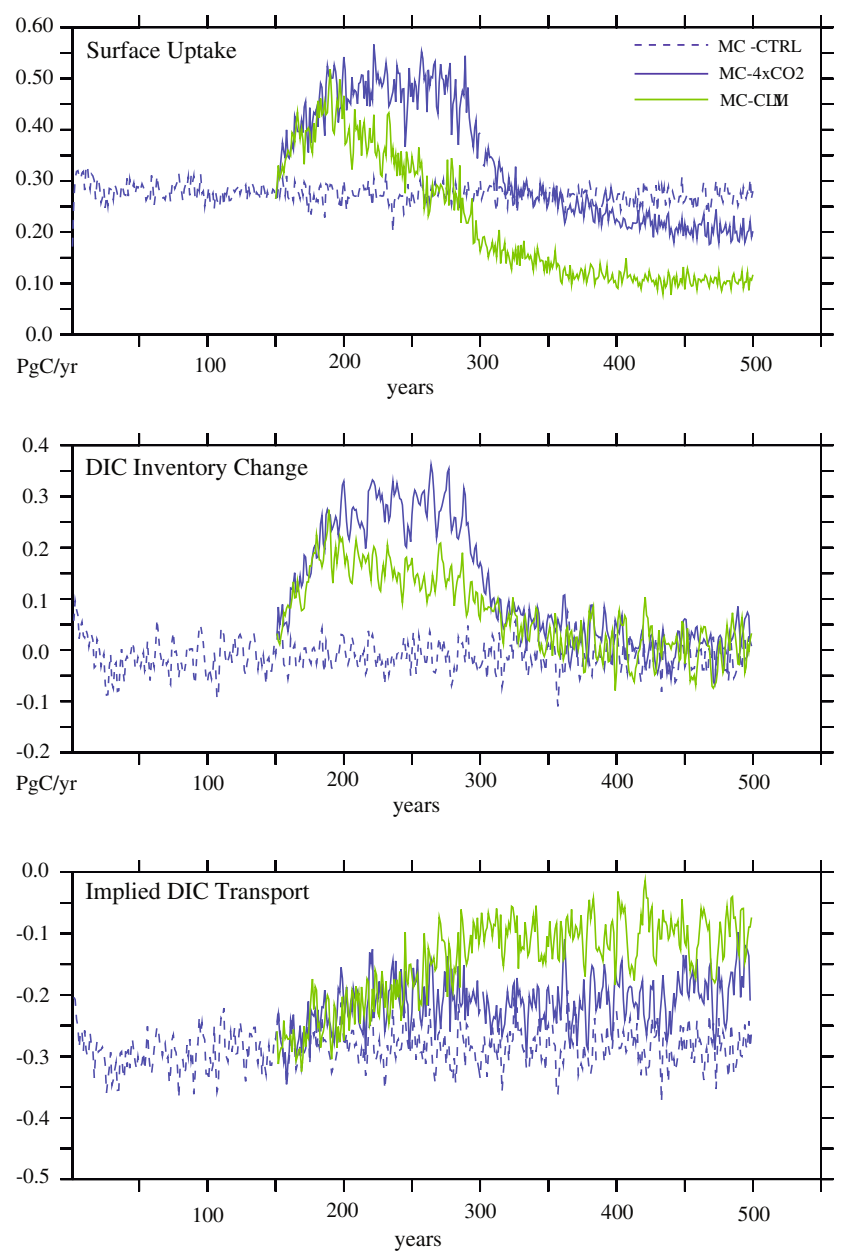

Fig. 9 North Atlantic $\mathrm{CO}_{2}$ budgets for the climate change experiment. Top is the surface uptake, middle is the change in DIC inventory, and bottom is the ocean transport of DIC implied by the difference of the two panels above. A positive residual indicates transport into the North Atlantic. Dashed lines are CTRL runs, and solid the $4 \mathrm{xCO} 2$ experiments. Blue MC-CTRL and MC-4xCO2 as in Fig. 6; green MC-CLIM

uptake further, with the timescale reducing such that North Atlantic $\mathrm{CO}_{2}$ uptake drops below preindustrial values whilst atmospheric $\mathrm{CO}_{2}$ is still rising.

The majority of these differences can be ascribed to the background ocean states produced by the different models. Although each control run attempts to model the same preindustrial ocean state, the resulting states differ due to different resolutions, processes, and boundary conditions. Differences in the biogeochemical models seemed to be of far less importance, given the large effects of differences in temperature, salinity, and diapycnal mixing provided by the different ocean models. It is reasonable to conclude that the details of the biogeochemical model are relatively unimportant when compared to deficiencies in the physical model, at least when it comes to assessing surface $\mathrm{CO}_{2}$ uptake in climate models. Considering the timescales on which $\mathrm{CO}_{2}$ uptake returns back to (and below) its preindustrial level, the inter-model differences were also greater than the details of the forcing scenario used, as shown by the similarities between the $\mathrm{L}-4 \mathrm{xCO} 2$ and $\mathrm{L}-650$ experiments.

The MO-CTRL run appears to have the most realistic surface state in the North Atlantic, and, of the experiments considered in this study, might be expected to provide the most realistic estimate of the surface uptake. However, the MOC strength in MO-CTRL is possibly too high (Talley et al. 2003), which may affect the degree of equilibration of the northward flowing water in the Atlantic (although the resolution of the model means that the northward flowing western boundary current that makes up the upper limb of the MOC in the Atlantic is still likely to be too broad and slow, even given a high maximum value of the streamfunction). The overestimation of the MOC strength may also affect the $\mathrm{CO}_{2}$ uptake via excessively deep mixed layers associated with increased deepwater formation. Much of the large difference in North Atlantic $\mathrm{CO}_{2}$ uptake responses seen between the $\mathrm{L}-4 \mathrm{xCO} 2$ and the $\mathrm{MC}-4 \mathrm{xCO} 2$ runs appears to be due to the different mixed layer depths and MOC strengths in the two runs, so an accurate representation of the MOC and diapycnal mixing is essential in modelling surface fluxes correctly.

Tying the MO-CTRL state to realistic values through the use of fixed boundary conditions gives a degree of accuracy in the ocean state unlikely to be realised in an atmosphere-ocean coupled model which is free to find its own equilibrium. Climate change experiments, however, require the use of an atmosphere model to provide the changing boundary conditions, meaning that the realism provided by fixed boundary conditions is harder to realise for climate change experiments. A wide range of models (e.g. Lenton et al. 2006; Friedlingstein et al. 2005) is currently used in the study of the ocean carbon system, with the comprehensive nature of Earth System Models requiring that they often use less sophisticated/low resolution components for computational efficiency. The results here would suggest that such models could produce an extremely wide variation in their estimates of time-dependent $\mathrm{CO}_{2}$ uptake by the ocean. Given the sensitivity of the $\mathrm{CO}_{2}$ uptake to the background ocean state, the results of this study suggest that it may be necessary to use anomaly coupling or flux adjustments with such models to ensure a good background ocean state in order to accurately model the uptake of $\mathrm{CO}_{2}$ in the future.

Ocean uptake of $\mathrm{CO}_{2}$ below preindustrial levels can be seen as an "outgassing" of the anthropogenic component of the $\mathrm{CO}_{2}$ flux. In agreement with Völker et al. (2002), this outgassing is a robust feature of all the $\mathrm{CO}_{2}$-increase experiments here. The timescale on which it occurs is, however, extremely model dependent, again tied to the 
representation of the background model physics. Using a box model, Völker et al. (2002) found outgassing of anthropogenic $\mathrm{CO}_{2}$ in the North Atlantic occurring 100 years before stabilisation of atmospheric $\mathrm{CO}_{2}$. The ocean general circulation models (OGCMs) used here show periods ranging from 50 years before stabilisation to 300 years after. Outgassing of anthropogenic $\mathrm{CO}_{2}$ in the North Atlantic before stabilisation of atmospheric $\mathrm{CO}_{2}$ levels is only seen in this study when the additional effects of a physical climate change are included, a factor that was not included in the Völker et al. (2002) study. The dependence of the timescale of the outgassing on the model physics implies that, if we are to make an estimate of the timescale likely to be observed in reality, it would be best to use the most realistic model and ocean state possible. In our experiments, the most realistic modern day ocean state is provided in the MO-CTRL run, however, two things stand in the way of using the $\mathrm{MO}-4 \mathrm{xCO} 2$ experiment to provide a realistic timescale for the outgassing of anthropogenic $\mathrm{CO}_{2}$ in the North Atlantic. First, the fixed boundary conditions mean we do not have an estimate of the effects of physical climate change for this run. Secondly, the 4xCO2 forcing scenario used is rather idealised, compared to, say the more likely SRES (Special Report on Emissions Scenarios) scenarios (Nakicenovic et al. 1999). Given that the L-650 and L-4xCO2 experiments show timescales for the outgassing of anthropogenic $\mathrm{CO}_{2}$ in the North Atlantic that are very similar to each other, the timescale (neglecting climate change effects) would seem not to be heavily dependent on the $\mathrm{CO}_{2}$ scenario used. Thus, it seems not unreasonable to use the $\mathrm{MO}-4 \mathrm{xCO} 2$ experiment as a basis for estimating a realistic timescale. To assess the effects of physical climate change, we can use the results of the MC-CLIM run. In the MC-CLIM experiment, including physical climate change effects shortened the total period of uptake of anthropogenic $\mathrm{CO}_{2}$ (from the start of the atmospheric $\mathrm{CO}_{2}$ forcing until $\mathrm{CO}_{2}$ uptake drops below preindustrial levels) in the North Atlantic from about 150 to 100 years, a reduction of about one-third. Assuming that a similar reduction in timescale can be applied to the $\mathrm{MO}-4 \mathrm{xCO} 2$ experiment, we find a total period of about 190 years of uptake of anthropogenic $\mathrm{CO}_{2}$ in the North Atlantic. It is difficult to relate these idealised scenarios to historical $\mathrm{CO}_{2}$ emissions, but taking the date of the stabilisation of atmospheric $\mathrm{CO}_{2}$ as a common point, this result implies that uptake of anthropogenic $\mathrm{CO}_{2}$ in the North Atlantic would drop below preindustrial levels roughly 50 years after stabilisation of atmospheric $\mathrm{CO}_{2}$ in the real world.

The results from Sect. 5 do suggest that it is possible to get a reasonable estimate of regional anthropogenic carbon inventories from current models. Despite their rather different background ocean states and surface $\mathrm{CO}_{2}$ uptake, all the models produce very similar levels of anthropogenic carbon stored in the North Atlantic. The differences in surface $\mathrm{CO}_{2}$ uptake are made up for by compensating differences in transport from further south in the Atlantic. This compensation agrees with the conclusion of Völker et al. (2002) that anthropogenic carbon inventories derived for the Atlantic do not constrain the surface fluxes well: they found that their modelled inventory of DIC could be used to imply a wide spread of surface carbon fluxes; the differing surface fluxes in the experiments here all produce similar inventories of anthropogenic DIC in the North Atlantic. Concerning the representation of the ocean carbon system in other models, the strategy of flux adjustments proposed above is perhaps not necessary if one is more concerned with getting the inventory of carbon correct than the surface uptake. Although Orr et al. (2001) found that there were significant inter-model differences in terms of regional anthropogenic carbon inventory as well as surface fluxes, the differences were found mainly in the Southern Ocean, and it may be that other regions are not so sensitive.

Transport of anthropogenic DIC into and out of the North Atlantic plays an important role in this study. All model configurations show a net export of DIC from the North Atlantic, but the transport response to increasing atmospheric $\mathrm{CO}_{2}$ does differ. In the configurations with higher overturning rates and deeper mixed layers (L$4 \mathrm{xCO} 2, \mathrm{MO}-4 \mathrm{xCO} 2$ ), export increases under anthropogenic $\mathrm{CO}_{2}$ forcing. On the other hand, in the coupled configuration with weaker MOCs (MC-4xCO2, where the MOC is static at a relatively weak $14 \mathrm{~Sv}$, and MC-CLIM where climate change causes the MOC to weaken further) there is a decrease in net export-an import of anthropogenic DIC. There is a discrepancy between observationally derived budgets, which imply that transport of anthropogenic DIC into the North Atlantic is large enough to not require any significant uptake at the surface to balance observed DIC levels (Roson et al. 2003; Macdonald et al. 2003), and numerical models, which all show significant uptake (e.g. Orr et al. 2001). There is, however, considerable uncertainty in both estimates. The results from the MC experiments, which show import of anthropogenic DIC, agree best with those observational estimates, despite the apparent errors in the surface state of MC-CTRL. This may indicate that the weaker MOC found in MC-CTRL provides a more accurate representation of the surface $\mathrm{CO}_{2}$ uptake due to the MOC than the stronger MOCs found in the other runs. The relative insensitivity of the DIC inventory in the North Atlantic means that the surface $\mathrm{CO}_{2}$ uptake and oceanic DIC transport are closely coupled, and the model spread found in the uptake thus applies equally well to the DIC transports. Previous model estimates of ocean transport of anthropogenic DIC in the Atlantic may therefore be unreliable. 
The dependence of North Atlantic $\mathrm{CO}_{2}$ uptake on the model physics shown here clearly implies that the use of the best ocean physics possible is required to get a realistic estimate of the likely evolution of carbon uptake and transport in the North Atlantic. The use of high-resolution ocean models with realistic temperature structures and diapycnal mixing levels is thus recommended. There is also the question of the evolution and impact of ocean biology on the $\mathrm{CO}_{2}$ uptake. Biological export of surface carbon has considerable scope for modifying global ocean $\mathrm{CO}_{2}$ uptake, and much more work needs to be done to assess accurately how marine biology might change in the future. The C4MIP model intercomparison project (Friedlingstein et al. 2005) has shown progress in at least in the physical models behind the biogeochemistry, and the use of SRES emissions scenarios (Nakicenovic et al. 1999) should allow better estimates of how $\mathrm{CO}_{2}$ uptake is likely to evolve in reality. Early results from a higher resolution, online version of the ECHAM5/MPI-OM/HAMOCC5 model with a full carbon cycle (J. Segschneider, personal communication) predict a reduction in North Atlantic $\mathrm{CO}_{2}$ uptake on a slightly longer timescale than that seen here in the MCCLIM experiment; this may well be due to the use of a less extreme $\mathrm{CO}_{2}$ forcing than used here.

\section{Conclusions}

- There are large inter-model differences in the magnitude and timing of the uptake of anthropogenic $\mathrm{CO}_{2}$ in the North Atlantic, even neglecting the uncertainties of possible future climate change. Differences in uptake are clearly linked to differences in the temperature and freshwater balance of the models' ocean surface, which can result from different boundary conditions (e.g. different climatological forcings, or coupled fields from an atmosphere model) or different model reactions to those boundary conditions.

- Neglecting physical climate change, the anthropogenic DIC inventory in the North Atlantic differs far less between the models than the surface $\mathrm{CO}_{2}$ uptake. Northward transport of anthropogenic DIC in the Atlantic is greater in the models with lower North Atlantic surface $\mathrm{CO}_{2}$ uptake.

- Physical climate change effects act to reduce anthropogenic $\mathrm{CO}_{2}$ uptake in the North Atlantic. Ocean surface warming, an increase in freshwater input and a reduction of the strength of the MOC all play a role in a more rapid increase of ocean $p \mathrm{CO}_{2}$ than is seen when physical climate changes are neglected. Shallower spring mixed layer depths act to reduce primary production in the North Atlantic, reducing the potential role for ocean biology in drawing down anthropogenic $\mathrm{CO}_{2}$.
- The outgassing of anthropogenic $\mathrm{CO}_{2}$ from the North Atlantic is likely to occur on centennial timescales, and may occur whilst levels of atmospheric $\mathrm{CO}_{2}$ are still rising. This timescale differs by several centuries in different models, and depends more on differences in the model equilibrium surface ocean state than on the choice of $\mathrm{CO}_{2}$ forcing scenario or on the physical effects of climate change. The best estimate from this study is that outgassing of anthropogenic $\mathrm{CO}_{2}$ from the North Atlantic would occur about 50 years after atmospheric $\mathrm{CO}_{2}$ stabilises.

Acknowledgments We would like to thank Patrick Wetzel and Ernst Maier-Reimer for advice and for access to the HAMOCC models, Johann Jungclaus for providing the climate data from the ECHAM5/MPI-OM model and the Deutsches Klimarechnung Zentrum for providing computing resources. We are indebted to Joachim Segschneider and the reviewers for their comments, which have led to a considerably improved manuscript.

\section{References}

Broecker WS (1982) Glacial to interglacial changes in ocean chemistry. Prog Oceanogr 11:151-197

Doney SC, Lindsay K, Caldeira K, Campin J-M, Drange H, Dutay JC, Follows M, Gao Y, Gnanadesikan A, Gruber N, Ishida A, Joos F, Madec G, Maier-Reimer E, Marshall JC, Matear RJ, Monfray P, Mouchet A, Najjar R, Orr JC, Plattner G-K, Sarmiento J, Schlitzer R, Slater R, Totterdell IJ, Weirig M-F, Yamanaka Y, Yool A (2004) Evaluating global ocean carbon models: the importance of realistic physics. Glob Biogeochem Cycles 18. doi:10.1029/2003GB002150

Friedlingstein P, Cox P, Betts R, Bopp L, von Bloh W, Brovkin DV, Eby S, Fung IM, Govindasamy B, John J, Jones C, Joos F, Kato T, Kawamiya M, Knorr W, Lindsay K, Matthews HD, Raddatz T, Rayner P, Reick C, Roeckner E, Schnitzler K-G, Schnur R, Strassmann K, Thompson S, Weaver AJ, Yoshikawa C, Zeng N (2005) Climate-carbon cycle feedback analysis, results from the C4MIP model intercomparison. J Clim 19:3337-3353

Gregory JM, Dixon KW, Stouffer RJ, Weaver AJ, Dreisschaert E, Eby M, Fichefet T, Hasumi H, Hu A, Jungclaus JH, Kamenkovich IV, Levermann A, Montoya M, Murakami S, Nawrath S, Oka A, Sokolov AP, Thorpe RB (2005) A model intercomparison of changes in the Atlantic thermohaline circulation in response to increasing atmospheric $\mathrm{CO}_{2}$ concentration. Geophys Res Lett 32. 10.1029/2005GL023209

Gruber N, Sarmiento JL, Stocker TF (1996) An improved method for detecting anthropogenic $\mathrm{CO}_{2}$ in the oceans. Glob Biogeocehm Cycles 10:809-837

Joos F, Plattner G-K, Stocker TF, Marchal O, Schmittner A (1999) Global warming and marine carbon cycle feedbacks on future atmospheric $\mathrm{CO}_{2}$. Science 284:464-467

Jungclaus JH, Botzet M, Haak H, Keenlyside N, Luo JJ, Latif M, Marotzke J, Mikolajewicz U, Roeckner E (2005) Ocean circulation and tropical variability in the coupled model ECHAM5/MPI-OM. J Clim 19:3952-3972

Key RM, Kozyr A, Sabine CL, Lee K, Wanninkhof R, Bullister JL, Feely RA, Millero FJ, Mordy C, Peng T-H (2004) A global ocean carbon climatology: results from Global Data Analysis 
Project (GLODAP). Glob Biogeochem Cycles 18. 10.1029/ 2004GB002247

Killworth PD (1996) Time interpolation of forcing fields in ocean models. J Phys Oceanogr 26:136-143

Lefevre N, Watson AJ (2004) A decrease in the sink for atmospheric $\mathrm{CO}_{2}$ in the North Atlantic. Geophys Res Lett 31. 10.1029/ 2003GL018957

Lenton TM, Williamson MS, Edwards NR, Marsh R, Price AR, Ridgwell AJ, Shepherd JG, Cox SJ (2006) The GENIE team. Millennial timescale carbon cycle and climate change in an efficient earth system model. Clim Dynam 26:687-711

Levitus S, Boyer TP, Conkright ME, O'Brien T, Antonov J, Stephens C, Stathoplos L, Johnson D, Gelfeld R (eds) (1998) NOAA Atlas NESDIS 18, World Ocean Database 1998, vol 1. National Oceanographic Data Center

Macdonald AM, Baringer MO, Wanninkhof R, Lee K, Wallace DWR (2003) A 1998-1992 comparison of inorganic carbon and its transport across $24.5^{\circ} \mathrm{N}$ in the Atlantic. Deep Sea Res II 50:3041-3064

Maier-Reimer E (1993) Geochemical cycles in an ocean general circulation model: preindustrial tracer distribution. Glob Biogeochem Cycles 7:645-677

Maier-Reimer E, Mikolajewicz U, Hasselmann K (1993) Mean circulation of the Hamburg LSG OGCM and its sensitivity to the thermohaline surface forcing. J Phys Oceanogr 23:731-757

Maier-Reimer E, Mikolajewicz U, Winguth A (1996) Future ocean uptake of $\mathrm{CO}_{2}$ : interaction between ocean circulation and biology. Clim Dynam 12:711-721

Maier-Reimer E, Kriest I, Segschneider J, Wetzel P (2005) The HAMburg Ocean Carbon Cycle model HAMOCC 5.1-Technical Description Release 1.1. Technical report 14/2005, Max-Planck Institute for Meteorology, Hamburg. http://www.edoc.mpg.de

Marsland SJ, Haak H, Jungclaus JH, Latif M, Ruske F (2003) The Max-Planck Institute global ocean/sea-ice model with orthogonal curvilinear coordinates. Ocean Modell 5:91-127

Nakicenovic N, Alcamo J, Davis G, de Vries B, Fenhann J, Gaffin S, Gregory K, Grübler A, Jung TY, Kram T, La Rovere EL, Michaelis L, Mori S, Morita T, Pepper W, Pitcher H, Price L, Riahi K, Roehrl A, Rogner H-H, Sankovski A, Schlesinger M, Shukla P, Smith S, Swart R, van Rooijen S, Victor N, Dadi Z (1999) IPCC Special Report on Emissions Scenarios. Cambridge University Press, Cambridge

Omar AM, Olsen A (2006) Reconstructing the time history of the airsea $\mathrm{CO}_{2}$ disequilibrium and its rate of change in the eastern subpolar North Atlantic, 1972-1989. Geophys Res Lett 33. doi: 10.1029/2005GL025425

Orr JC, Maier-Reimer E, Mikolajewicz U, Monfray P, JL Sarmiento JL, Toggweiler JR, Taylor NK, Palmer J, Gruber N, Sabine CL, Le Quere C, Key RM, Boutin J (2001) Estimates of anthropogenic carbon uptake from four three-dimensional global ocean models. Glob Biogeochem Cycles 15(1):43-60

Pacanowski RC, Philander SGH (1981) Parameterization of vertical mixing in numerical models of tropical oceans. J Phys Oceanogr 11:1443-1451

Roeckner E, Bäuml G, Bonaventura L, Brokopf R, Esch M, Giorgetta M, Hagemann S, Kirchner I, Kornblueh L, Manzini E, Rhodin A, Schlese U, Schulzweida U, Tompkins A (2003) The Atmospheric General Circulation Model ECHAM5. Report 349, MaxPlanck Institute for Meteorology, Hamburg, November 2003. http://www.mpimet.mpg.de/en/wissenschaft/publikationen/ reports.html

Roson G, Rios AF, Lavin A, Perez FF, Bryden HL (2003) Carbon distribution, fluxes and budgets in the subtropical North Atlantic Ocean $\left(24.5^{\circ} \mathrm{N}\right)$. J Geophys Res 108:3144

Röske F (2005) Global oceanic heat and fresh water forcing datasets based on ERA-40 and ERA-15. Technical report 13, Max-Planck Institute for Meteorology. http://www.edoc.mpg.de

Sabine CL, Feely RA, Gruber N, Key RM, Lee K, Bullister JL, Wanninkhof R, Wong CS, Wallace DR, Tilbrook B, Millero FJ, Peng T-H, Kozyr A, Ono T, Rios AF (2004) The oceanic sink for anthropogenic $\mathrm{CO}_{2}$. Science 305:367-371

Sarmiento JL, Le Quere C (1996) Oceanic carbon dioxide uptake in a model of century-scale global warming. Science 274:1346-1350

Sarmiento JL, Gruber N (2006) Ocean biogeochemical dynamics. Princeton University Press, Englewood Cliffs

Talley LD, Reid JL, Robbins PE (2003) Data-based meridional overturning streamfunctions for the global ocean. J Clim 16:3213-3226

Timmreck C, Schulz M (2004) Significant dust simulation differences in nudged and climatological operation mode of the AGCM ECHAM. J Geophys Res 109. doi:10.1029/2003JD004381

Völker C, Wolf-Gladrow DA, Wallace DWR (2002) On the role of heat fluxes in the uptake of anthropogenic carbon in the North Atlantic. Glob Biogeochem Cycles 16(4). doi:10.1029/2002GB001897

Wanninkhof R (1992) Relationship between wind speed and gas exchange over the ocean. J Geophys Res 97:7373-7382 